\title{
Nivolumab-related severe thrombocytopenia in a patient with relapsed lung adenocarcinoma: a case report and review of the literature
}

Takeo Hasegawa', Yuki Ozaki', Takuya Inoue', Yuzuru Watanabe', Mitsuro Fukuhara', Takumi Yamaura', Satoshi Muto ${ }^{1}$, Naoyuki Okabe', Mitsunori Higuchi², Yutaka Shio ${ }^{1}$ and Hiroyuki Suzuki ${ }^{1 *}$

\begin{abstract}
Background: Immune checkpoint inhibitor therapy has changed the standard drug therapy for relapsed or advanced non-small cell lung cancer; its efficacy is well-recognized by pulmonary physicians, oncologists, and thoracic surgeons. Nivolumab, one of the anti-programmed cell death 1 antibodies, was the first immune checkpoint inhibitor to be approved and is used as a standard second-line regimen for patients with non-small cell lung cancer irrespective of the expression of programmed cell death ligand 1. Programmed cell death 1 antibodies have been generally confirmed to be less toxic than conventional cytotoxic chemotherapy, although unusual immune-related adverse events such as type I diabetes mellitus, adrenal failure, and myasthenia gravis may occur with a very low incidence. A case of severe grade $V$ immune-related thrombocytopenia after two courses of nivolumab as second-line therapy for relapsed non-small cell lung cancer is reported.

Case presentation: An 82-year-old Japanese woman with relapsed lung adenocarcinoma was treated with nivolumab as second-line systemic therapy at our institute. Her laboratory data indicated thrombocytopenia suspected to be an immune-related adverse event following two courses of nivolumab. Subsequently, she developed a massive pulmonary hemorrhage and left cerebral infarction despite intensive treatment including systemic steroid therapy. Although there have been a few reports of thrombocytopenia caused by nivolumab, this is the first report of grade $V$ thrombocytopenia following administration of nivolumab for relapsed non-small cell lung cancer.

Conclusion: A very difficult case of grade $V$ immune-related thrombocytopenia after the administration of nivolumab as second-line therapy for relapsed lung adenocarcinoma was described. Immune-related thrombocytopenia is a rare adverse event, but it must be considered a possible complication because it may become critical once it has occurred.
\end{abstract}

Keywords: Nivolumab, Immune checkpoint inhibitor, Non-small cell lung cancer, Immune-related thrombocytopenia

\footnotetext{
* Correspondence: hiro@fmu.ac.jp

'Department of Chest Surgery, Fukushima Medical University School of

Medicine, 1 Hikarigaoka, Fukushima 960-1295, Japan

Full list of author information is available at the end of the article
}

(c) The Author(s). 2019 Open Access This article is distributed under the terms of the Creative Commons Attribution 4.0 International License (http://creativecommons.org/licenses/by/4.0/), which permits unrestricted use, distribution, and reproduction in any medium, provided you give appropriate credit to the original author(s) and the source, provide a link to the Creative Commons license, and indicate if changes were made. The Creative Commons Public Domain Dedication waiver (http://creativecommons.org/publicdomain/zero/1.0/) applies to the data made available in this article, unless otherwise stated. 


\section{Background}

Lung cancer is the leading cause of cancer death in the world. Platinum-based combination cytotoxic chemotherapy was the only standard treatment regimen for advanced or relapsed non-small cell lung cancer (NSCLC) for over a decade. In 2015, the programmed cell death 1 (PD-1) antibody nivolumab was confirmed to be effective and was first approved by the US Food and Drug Administration. Today, immune checkpoint inhibitors (ICIs), such as the anti-PD-1 antibodies nivolumab $[1,2]$ and pembrolizumab [3] or the anti-programmed cell death ligand 1 (PD-L1) antibodies atezolizumab [4] and durvalumab [5], are recognized as standard second-line therapies for advanced or relapsed NSCLC, and use of ICIs is expanding to many other malignancies. ICIs are generally recognized to be less toxic than cytotoxic chemotherapy, but they may cause unusual immunerelated adverse events (ir-AEs), such as thyroiditis, type I diabetes mellitus, adrenal failure, or myasthenia gravis, while thrombocytopenia has been reported in only a few cases of advanced NSCLC [6-9]. The first case of grade $\mathrm{V}$ thrombocytopenia caused by nivolumab in a patient with relapsed NSCLC is presented, and the purpose of this report is to act as a warning that ICI-induced fatal thrombocytopenia could occur, although it is very rare.

\section{Case presentation}

An 82-year-old Japanese woman, who had never smoked tobacco, with a past medical history of hypertension, glaucoma, and slight renal dysfunction underwent left upper lobectomy with upper mediastinal lymph node dissection for lung cancer. She had been an office worker with telephone-related duties, and she was taking antihypertensives, proton pump inhibitors, acetaminophen, expectorants, and eye drops for glaucoma. The pathological diagnosis was T3N0M0 stage IIB adenocarcinoma with parietal pleural invasion (Fig. 1a). She had a point mutation of L858R in exon 21 of the epidermal growth factor receptor (EGFR) gene, and immunohistochemistry was weakly positive for PD-L1 (Fig. 1b).

Seven months after surgery, she was diagnosed as having contralateral pulmonary metastasis and started the first-line tyrosine kinase inhibitor gefitinib. However, gefitinib was discontinued because of the development of interstitial lung disease (ILD). After cessation of gefitinib, disease progression was seen on positron emission tomography, but her Eastern Cooperative Oncology Group (ECOG) performance status was 0. Because she had leftsided back pain due to metastasis to the left pleura with chest wall invasion around the third thoracic spine, palliative irradiation to her chest wall was performed. After $30 \mathrm{~Gy}$ of palliative irradiation, she was given nivolumab $3 \mathrm{mg} / \mathrm{kg}$ every 2 weeks as a second-line therapy (Fig. 2). During the first two cycles of nivolumab treatment, no adverse events (AEs) were observed, and her platelet count was almost $180 \times 10^{3} / \mu \mathrm{L}$ before and after administration of nivolumab. However, laboratory data before the third cycle of nivolumab showed that her platelets were extremely low $(2000 / \mu \mathrm{L})$, although her hemoglobin and white blood cell count $(10.6 \mathrm{~g} / \mathrm{dL}$ and $4500 / \mu \mathrm{L}$, respectively) remained unchanged compared to the previous examination. Based on this result, she was admitted to our hospital urgently that same day.

On arrival, she was hemodynamically stable (blood pressure $128 / 79 \mathrm{mmHg}$, pulse rate 56 beats/minute, temperature $36.2^{\circ} \mathrm{C}$ ). There was no abnormal finding on her respiratory sounds. Her cardiac, abdominal, and neurological examinations were also without focal findings. Over time, symptoms such as nasal bleeding and bilateral purpura of her lower limbs developed. Her human leukocyte antigen (HLA) subtype was checked after emergency admission, and it was discovered that she had HLA-DRB1*0405 and DRB0901. Although she underwent a platelet transfusion every day, her platelet count remained low (Fig. 3), and platelet-associated immunoglobulin G (PA-IgG) antibody was relatively high (223 ng/10 ${ }^{7}$ cells). She gradually developed hemoptysis

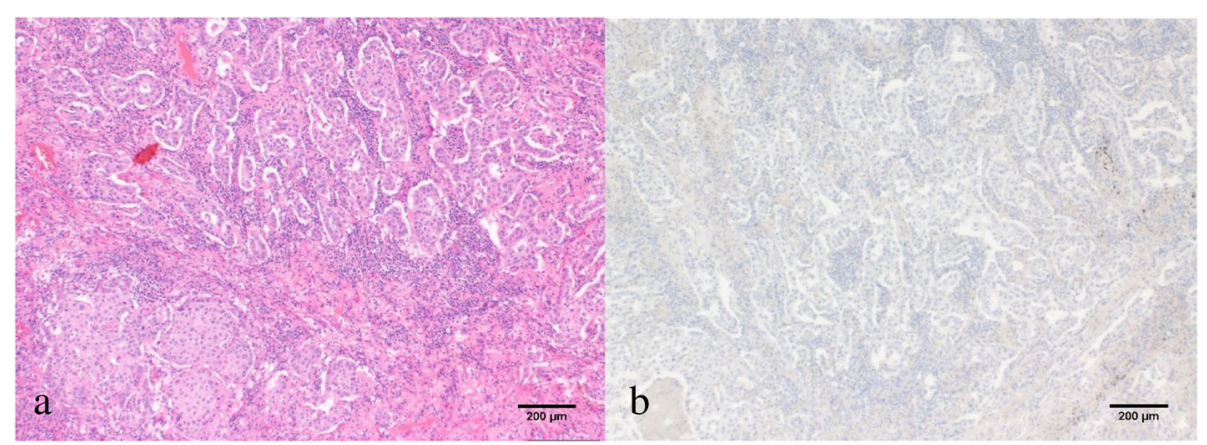

Fig. 1 Pathological findings of the resected specimen. a Hematoxylin and eosin staining shows invasive adenocarcinoma of papillary predominant type. $\mathbf{b}$ Immunohistochemistry was weakly positive for programmed cell death ligand 1 (PD-L1) (SP-142 antibody) 

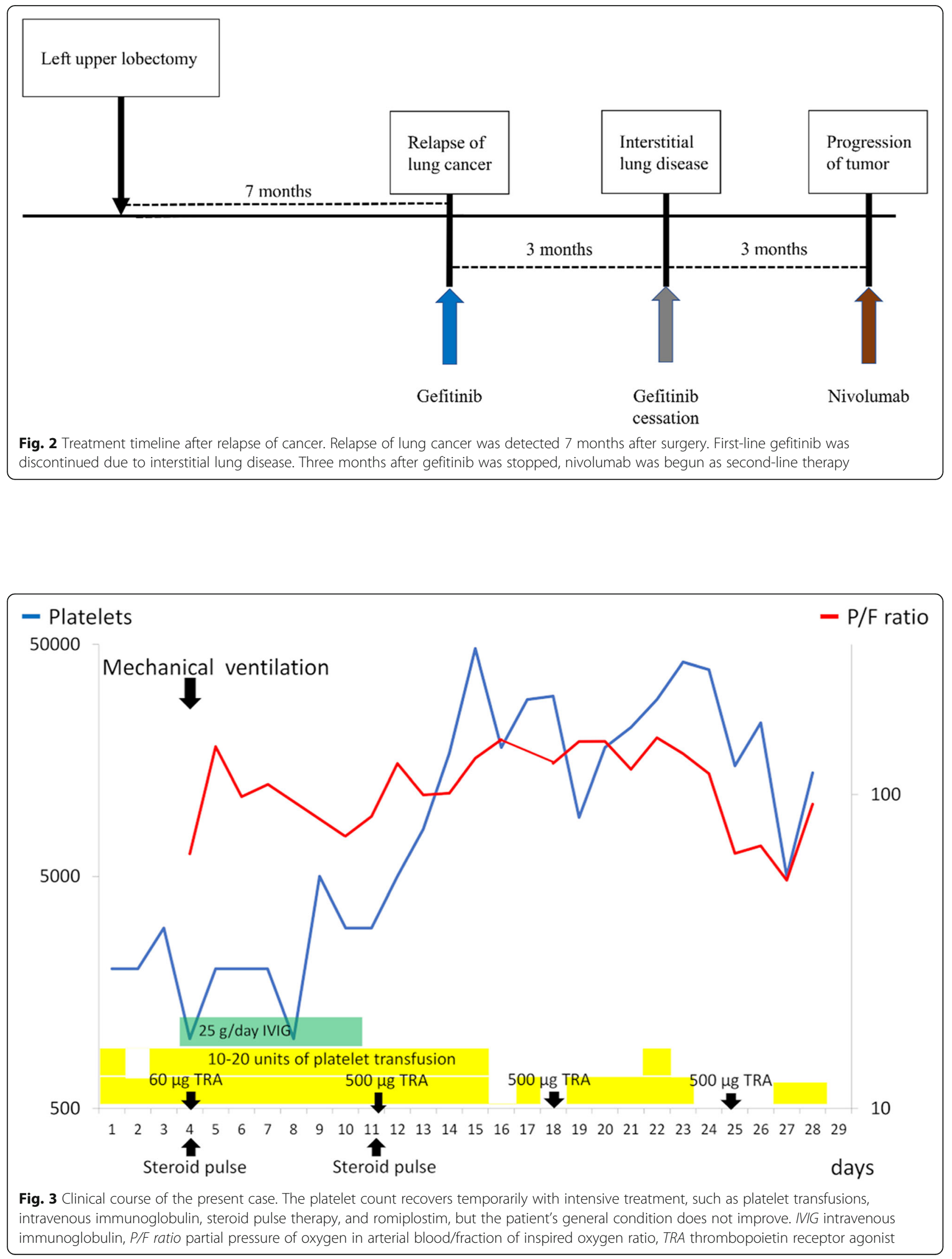
and dyspnea because of alveolar hemorrhage. Four days after admission, she required mechanical ventilation, and she developed upper gastrointestinal bleeding, macroscopic hematuria, renal dysfunction, and liver dysfunction. Intravenous immunoglobulin (IVIG) for 7 days, methylprednisolone pulse with maintenance therapy, and romiplostim (recombinant thrombopoietin receptor agonist; TRA) every week were then added to her treatment. Fifteen days after admission, her platelet counts recovered slightly; however, paradoxical cerebral infarction occurred at the left claustrum. Her general condition did not improve despite intensive therapy (Figs. 3, 4); she died 29 days after admission. There was fatal diffuse microscopic bleeding in the lungs, kidneys, pancreas, and ovaries on autopsy. On the other hand, analysis of the lung tumor showed necrotic change, probably induced by nivolumab, because immunohistochemistry showed CD8-positive tumor-infiltrating lymphocytes that were focally positive around the carcinoma (Fig. 4d). Bacterial pneumonia with Grampositive cocci was also found, but there was no interstitial pneumonia. Based on the above findings, immune thrombocytopenia induced by nivolumab was determined to be the cause of death.

\section{Discussion and conclusions}

A case of severe grade $\mathrm{V}$ thrombocytopenia caused by nivolumab in a patient with relapsed NSCLC was reported because this is an educational case and a warning for all physicians and surgeons prescribing ICIs, regardless of the carcinoma. While the pathogenesis of nivolumab-related thrombocytopenia remains uncertain, it is postulated to mimic idiopathic thrombocytopenic purpura (ITP). In the present case, the mechanism of immune thrombocytopenia was likely to have been caused mainly by PA-IgG antibodies produced by activated lymphocytes. The approved treatments for thrombocytopenia most frequently recommended and
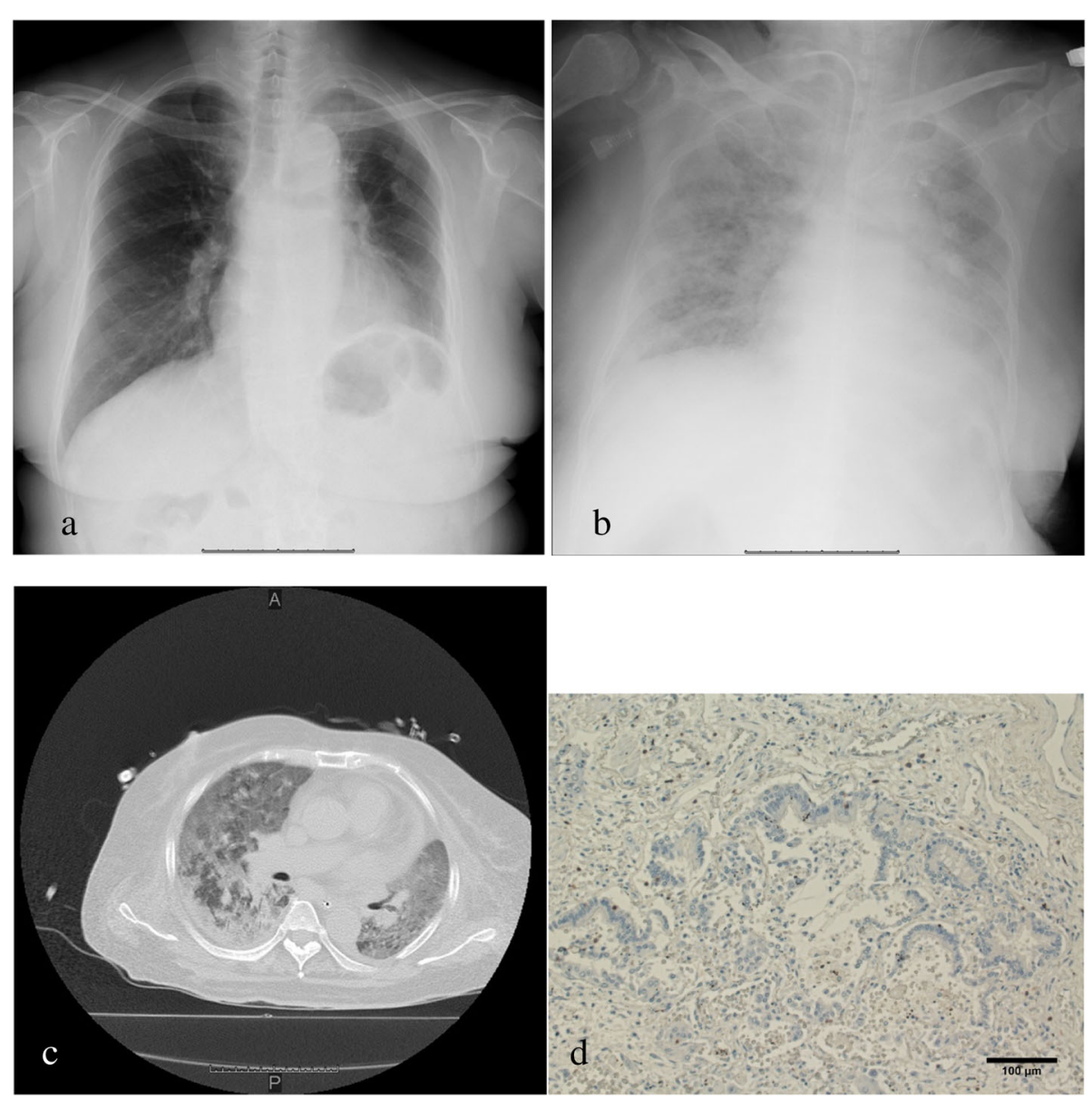

Fig. 4 Chest X-ray, computed tomography findings, and immunohistochemistry at autopsy after thrombocytopenia. a Chest X-ray on admission for thrombocytopenia shows no noteworthy findings. b, c Chest X-ray and computed tomography scan at 24 days after admission show reduced bilateral permeability. $\mathbf{d}$ Immunohistochemistry at autopsy. CD8-positive tumor-infiltrating lymphocytes are focally positive, probably induced by nivolumab 
Table 1 Reported cases of immune-related thrombocytopenia induced by nivolumab in patients with non-small cell lung cancer

\begin{tabular}{lllllllll}
\hline Author (reference) & Year & Age (years)/sex & Cycle & PLT lowest count & PA-lgG (ng/10 ${ }^{7}$ cells) & Treatment & Other ir-AE & Outcome \\
\hline Bagley et al. [6] & 2016 & $34 / \mathrm{M}$ & 8 & $33,000 / \mu \mathrm{L}$ & NR & TRA & None & Recovered \\
Karakas et al. [7] & 2017 & $78 / \mathrm{M}$ & 6 & $5000 / \mu \mathrm{L}$ & NR & $\mathrm{S}$ & None & Died of cancer \\
Jotatsu et al. [8] & 2018 & $62 / \mathrm{M}$ & 2 & $1600 / \mu \mathrm{L}$ & 473 & $\mathrm{~S}$ & Hashimoto's disease Recovered \\
Tokumo et al. [9] & 2018 & $56 / \mathrm{F}$ & 3 & $19,000 / \mu \mathrm{L}$ & $\mathrm{NR}$ & $\mathrm{S}, \mathrm{I}$ & Pancytopenia & Died of cancer \\
Present case & 2018 & $82 / \mathrm{F}$ & 2 & $2000 / \mu \mathrm{L}$ & 223 & $\mathrm{~S}, \mathrm{l}, \mathrm{TRA}$ & None & Died of AE \\
\hline
\end{tabular}

$A E$ adverse event, $F$ female, $/$ immunoglobulin, ir- $A E$ immune-related adverse event, $M$ male, NR not reported, $P A-l g G$ platelet-associated immunoglobulin $G, P L T$ platelets, $S$ steroid therapy, TRA thrombopoietin receptor agonist

used are steroids, IVIG, TRAs, platelet transfusion, splenectomy, and other immunosuppressive agents such as azathioprine and rituximab [10]. Only a few cases of nivolumab-induced thrombocytopenia in patients with NSCLC have been reported to date (Table 1) [6-9], although none of these cases was fatal.

The present patient had severe systemic symptoms followed by bleeding from multiple organs and paradoxical cerebral infarction. She did not recover despite intensive therapy including steroid pulse therapy, a TRA, platelet transfusion, IVIG, mechanical ventilation, and so on. Nomura et al. reported that patients with ITP who had the HLA-DRB1*0410 allele were extremely resistant to steroid therapy [11]. The present patient did not have the HLA-DRB1*0410 allele, but she had HLADRB1*0405, which is the second most frequent allele in patients with ITP who are resistant to steroid therapy. This may explain why she had a weak response to steroid therapy. On the other hand, cerebral infarction in the present case might have been related to the IVIG she received. The pathogenesis of the subsequent brain infarction is thought to involve alteration of blood consistency after many doses of IVIG [12]. For other ICIs, there are also a limited number of reports of immune thrombocytopenia induced by pembrolizumab. Le Roy et al. reported two cases of thrombocytopenia in patients with melanoma related to pembrolizumab [13], and there are no reports of thrombocytopenia induced by atezolizumab in the English-language literature. In patients with malignant melanoma, there are also several reports of ICI-induced thrombocytopenia related to nivolumab [14-16].

Pillai et al. reported a large-scale systematic comparison of the toxicity profile of PD-1 or PD-L1 inhibitors in patients with NSCLC [17]. In that report, thrombocytopenia was not described as a major $\mathrm{AE}$, and we also recognized ICI-induced thrombocytopenia as a rare AE. Recently, Delanoy et al. reported hematological ir-AEs induced by anti-PD-1 or anti-PD-L1 immunotherapy [18]. They reported grade 2 or worse hematological ir-AEs in 35 patients (3.7\%), and immune thrombocytopenia was seen in 9 patients $(0.9 \%)$. Two patients had hemorrhagic symptoms, although grade $\mathrm{V}$ thrombocytopenia was not seen.
Two patients did not response to steroids or IVIG and were treated with TRAs or rituximab. They concluded that immunological cytopenia is a rare but potentially serious complication of anti-PD-1 or anti-PD-L1 immunotherapies. Another ICI, ipilimumab, which is a cytotoxic T lymphocyte antigen- 4 antibody, has been reported to induce immune thrombocytopenia [19]. In most cases treated by ICIs, relatively frequent AEs such as fatigue and diarrhea, or ir-AEs such as hypothyroidism or pneumonitis, could be managed by multidisciplinary treatment, although life-threatening AEs such as immune thrombocytopenia could occur. We have to consider that ICIs are not only long-lasting and effective drugs in patients with NSCLC, but they also have the possibility of causing severe ir-AEs, including thrombocytopenia.

A very difficult case of grade $\mathrm{V}$ immune-related thrombocytopenia after the administration of nivolumab as second-line therapy in a patient with relapsed lung adenocarcinoma was described. We should always consider that ICI treatment can lead to AEs that are difficult to predict, and a systematic support framework for irAEs and their predictive biomarkers should be established.

\section{Abbreviations}

AE: Adverse event; ECOG: Eastern Cooperative Oncology Group; EGFR: Epidermal growth factor receptor; HLA: Human leukocyte antigen; ICI: Immune checkpoint inhibitor; ILD: Interstitial lung disease; ir-AE: Immunerelated adverse event; ITP: Idiopathic thrombocytopenic purpura; IVIG: Intravenous immunoglobulin; NSCLC: Non-small cell lung cancer; PA-IgG: Platelet-associated IgG; PD-1: Programmed cell death 1; PD-L1: Programmed cell death ligand 1; TRA: Thrombopoietin receptor agonist

\section{Acknowledgements \\ The authors would like to thank Forte Science Communications (Tokyo, Japan) for English language editing.}

\section{Authors' contributions}

TH prepared the main manuscript and abstract. $\mathrm{MH}$ and $\mathrm{HS}$ played a major role in editing, reviewing, and adding to the manuscript. YO, TI, YW, MF, TY, $\mathrm{SM}, \mathrm{NO}$, and $\mathrm{YS}$ all helped treat the patient together. All authors read and approved the final manuscript. 


\section{Availability of data and materials}

All references may be accessed via hyperlink. No datasets were used in the preparation of this manuscript.

\section{Ethics approval and consent to participate}

The Ethics Committee of Fukushima Medical University approved the study.

\section{Consent for publication}

Written, informed consent was obtained from the family of the patient for publication of this case report and any accompanying images. A copy of the written consent is available for review by the Editor-in-Chief of this journal.

\section{Competing interests}

The authors declare that they have no competing interests.

\section{Author details}

'Department of Chest Surgery, Fukushima Medical University School of Medicine, 1 Hikarigaoka, Fukushima 960-1295, Japan. ²Department of Chest Surgery, Fukushima Medical University Aizu Medical Center, Fukushima, Japan.

Received: 15 February 2019 Accepted: 27 August 2019 Published online: 24 October 2019

\section{References}

1. Brahmer J, Reckamp KL, Baas P, Crino L, Eberhardt WE, Poddubskaya E, Antonia S, Pluzanski A, Vokes EE, Holgado E, et al. Nivolumab versus Docetaxel in Advanced Squamous-Cell Non-Small-Cell Lung Cancer. N Engl J Med. 2015;373:123-35.

2. Borghaei H, Paz-Ares L, Horn L, Spigel DR, Steins M, Ready NE, Chow LQ, Vokes EE, Felip E, Holgado E, et al. Nivolumab versus Docetaxel in Advanced Nonsquamous Non-Small-Cell Lung Cancer. N Engl J Med. 2015;373:1627-39.

3. Reck M, Rodriguez-Abreu D, Robinson AG, Hui R, Csoszi T, Fulop A, Gottfried M, Peled N, Tafreshi A, Cuffe S, et al. Pembrolizumab versus Chemotherapy for PD-L1-Positive Non-Small-Cell Lung Cancer. N Engl J Med. 2016;375:1823-33.

4. Rittmeyer A, Barlesi F, Waterkamp D, Park K, Ciardiello F, von Pawel J, Gadgeel SM, Hida T, Kowalski DM, Dols MC, et al. Atezolizumab versus docetaxel in patients with previously treated non-small-cell lung cancer (OAK): a phase 3, open-label, multicentre randomised controlled trial. Lancet. 2017;389:255-65.

5. Antonia SJ, Villegas A, Daniel D, Vicente D, Murakami S, Hui R, Yokoi T, Chiappori A, Lee KH, de Wit M, et al. Durvalumab after Chemoradiotherapy in Stage III Non-Small-Cell Lung Cancer. N Engl J Med. 2017;377:1919-29.

6. Bagley SJ, Kosteva JA, Evans TL, Langer CJ. Immune thrombocytopenia exacerbated by nivolumab in a patient with non-small-cell lung cancer. Cancer Treat Commun. 2016;6:20-3.

7. Karakas Y, Yuce D, Kilickap S. Immune Thrombocytopenia Induced by Nivolumab in a Metastatic Non-Small Cell Lung Cancer Patient. Oncol Res Treat. 2017:40:621-2

8. Jotatsu T, Oda K, Yamaguchi Y, Noguchi S, Kawanami T, Kido T, Satoh M, Yatera K. Immune-mediated thrombocytopenia and hypothyroidism in a lung cancer patient treated with nivolumab. Immunotherapy. 2018;10:85-91.

9. Tokumo K, Masuda T, Miyama T, Miura S, Yamaguchi K, Sakamoto S, Horimasu Y, Nakashima T, Miyamoto S, Yoshida T, et al. Nivolumab-induced severe pancytopenia in a patient with lung adenocarcinoma. Lung Cancer. 2018;119:21-4.

10. Weide R, Feiten S, Friesenhahn V, Heymanns J, Kleboth K, Thomalla J, van Roye C, Koppler H. Outpatient Management of Patients with Immune Thrombocytopenia (ITP) by Hematologists 1995-2014. Oncol Res Treat. 2016;39:41-4.

11. Nomura S, Matsuzaki T, Ozaki Y, Yamaoka M, Yoshimura C, Katsura K, Xie GL, Kagawa $H$, Ishida T, Fukuhara S. Clinical significance of HLA-DRB1*0410 in Japanese patients with idiopathic thrombocytopenic purpura. Blood. 1998; 91:3616-22

12. Al-Riyami AZ, Lee J, Connolly M, Shereck E. Cerebral sinus thrombosis following IV immunoglobulin therapy of immune thrombocytopenia purpura. Pediatr Blood Cancer. 2011;57:157-9.

13. Le Roy A, Kempf E, Ackermann F, Routier E, Robert C, Turpin A, Marabelle A, Mateus C, Michot JM, Lambotte O. Two cases of immune thrombocytopenia associated with pembrolizumab. Eur J Cancer. 2016;54:172-4.

14. Pfohler C, Eichler H, Burgard B, Krecke N, Muller CSL, Vogt T. A Case of Immune Thrombocytopenia as a Rare Side Effect of an Immunotherapy with PD1-Blocking Agents for Metastatic Melanoma. Transfus Med Hemother. 2017:44:426-8.

15. Kanameishi S, Otsuka A, Nonomura Y, Fujisawa A, Endo Y, Kabashima K. Idiopathic thrombocytopenic purpura induced by nivolumab in a metastatic melanoma patient with elevated PD-1 expression on B cells. Ann Oncol. 2016;27:546-7.

16. Inadomi K, Kumagai H, Arita S, Tsuruta N, Takayoshi K, Mishima K, Ota S, Tanaka M, Okumura Y, Sagara K, et al. Bi-cytopenia possibly induced by antiPD-1 antibody for primary malignant melanoma of the esophagus: A case report. Medicine (Baltimore). 2016;95:e4283.

17. Pillai RN, Behera M, Owonikoko TK, Kamphorst AO, Pakkala S, Belani CP, Khuri FR, Ahmed R, Ramalingam SS. Comparison of the toxicity profile of PD-1 versus PD-L1 inhibitors in non-small cell lung cancer: A systematic analysis of the literature. Cancer. 2018;124:271-7.

18. Delanoy N, Michot JM, Comont T, Kramkimel N, Lazarovici J, Dupont R, Champiat S, Chahine C, Robert C, Herbaux C, et al. Haematological immunerelated adverse events induced by anti-PD-1 or anti-PD-L1 immunotherapy: a descriptive observational study. Lancet Haematol. 2019;6:e48-57.

19. Kopecky J, Trojanova P, Kubecek O, Kopecky O. Treatment possibilities of ipilimumab-induced thrombocytopenia--case study and literature review. Jpn J Clin Oncol. 2015:45:381-4.

\section{Publisher's Note}

Springer Nature remains neutral with regard to jurisdictional claims in published maps and institutional affiliations.

Ready to submit your research? Choose BMC and benefit from:

- fast, convenient online submission

- thorough peer review by experienced researchers in your field

- rapid publication on acceptance

- support for research data, including large and complex data types

- gold Open Access which fosters wider collaboration and increased citations

- maximum visibility for your research: over $100 \mathrm{M}$ website views per year

At $\mathrm{BMC}$, research is always in progress.

Learn more biomedcentral.com/submissions 